\title{
The natech events during the 17 August 1999 Kocaeli earthquake: aftermath and lessons learned
}

\author{
S. Girgin \\ European Commission, Joint Research Center, Institute for the Protection and Security of the Citizen, \\ TP 361, Via E. Fermi 2749, 21027 Ispra (VA), Italy
}

Received: 5 February 2011 - Accepted: 16 March 2011 - Published: 21 April 2011

\begin{abstract}
Natural-hazard triggered technological accidents (natechs) at industrial facilities have been recognized as an emerging risk. Adequate preparedness, proper emergency planning, and effective response are crucial for the prevention of natechs and mitigation of the consequences. Under the conditions of a natural disaster, the limited resources, the possible unavailability of mitigation measures, and the lack of adequate communication complicate the management of natechs. The analysis of past natechs is crucial for learning lessons and for preventing or preparing for future natechs. The 17 August 1999, Kocaeli earthquake, which was a devastating disaster hitting one of the most industrialized regions of Turkey, offers opportunities in this respect. Among many natechs that occurred due to the earthquake, the massive fire at the TUPRAS Izmit refinery and the acrylonitrile spill at the AKSA acrylic fiber production plant were especially important and highlight problems in the consideration of natechs in emergency planning, response to industrial emergencies during natural hazards, and information to the public during and following the incidents. The analysis of these events shows that even the largest and seemingly well-prepared facilities can be vulnerable to natechs if risks are not considered adequately.
\end{abstract}

\section{Introduction}

The Kocaeli earthquake on 17 August $1999\left(M_{\mathrm{w}}=7.4\right)$ was one of the most devastating natural disasters in the modern history of Turkey. Occurring at 03:02 LT, the earthquake caused about 17500 fatalities and 44000 injured, affected 15 million people, and resulted in total property damage of over 15 billion USD. The area struck by the earthquake is

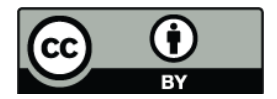

Correspondence to: S. Girgin (serkan.girgin@jrc.ec.europa.eu) one of the industrial heartlands of the country; it is densely populated and heavily industrialized, accounting for $35 \%$ of the gross national product (Özmen, 2000; Durukal and Erdik, 2008). The earthquake caused significant structural damage and machine and equipment loss at industrial facilities (Johnson et al., 2000; Rahnama and Morrow, 2000; Suzuki, 2002; Sezen and Whittaker, 2006; Durukal and Erdik, 2008), which led to many natech events ranging from small-sized hazardous substance releases to enormous fires (Steinberg et al., 2001; Steinberg and Cruz, 2004).

Among these events, two were especially noteworthy due to their extents and consequences: the massive fire at the TUPRAS Izmit refinery in Korfez, Kocaeli and the acrylonitrile spill at the AKSA acrylic fiber production plant in Ciftlikkoy, Yalova. The fire at the refinery lasted for 5 days and could only be extinguished by international support (Danış and Görgün, 2005). The spill of $6500 \mathrm{t}$ of acrylonitrile (AN), a toxic substance, damaged domestic animals, affected agricultural activities, endangered public health, and resulted in environmental pollution that required 5 years of continuous treatment for reclamation (Bayer, 1999; Zanbak, 2008). Both events required the evacuation of the settlements in the vicinity of the facilities and hampered search and rescue operations. There were also considerable economical losses.

Despite their adverse consequences, these natech events and their aftermath provide valuable information and lessons for natech risk management and shed light on what should and should not be done in case of such emergencies. In this study, first a detailed description of the events is given to emphasize what went wrong, and then the recovery, restoration and remediation work completed during the past decade are reported. Moreover, weaknesses in response to and management of the events are discussed and recommendations are made for better natech risk management. The presented lessons learned from the case studies can be useful, not only for Turkey but also for other natech-prone countries. 


\section{TUPRAS Izmit refinery fire}

Turkish Petroleum Refineries Corp. (TUPRAS) was founded in 1983 with the aim of uniting the administration and management of all public refineries in Turkey. Initially it was a state-owned corporation, but between 1991-2005 it was gradually privatized. Currently, $51 \%$ of its shares belong to the private sector and the remainder is on the stock exchange. Being Turkey's only producer in the refining sector and its largest industrial corporation, TUPRAS operates 4 refineries in Izmit, Izmir, Kirikkale and Batman with crude-oil processing capacities of 11.0, 11.0, 5.0 and 1.1 million t/year, respectively.

The TUPRAS Izmit refinery located on the northern coast of Izmit Bay at Korfez, Kocaeli, is the flagship of TUPRAS. It was founded in 1961 as a joint venture of Turkish Petroleum Corp. (TPAO) and California Texas Oil Corp. (CALTEX) under the name of Istanbul Petroleum Refinery Corp. (IPRAS). CALTEX shares were transferred to TPAO in 1972 and all shares were transferred to TUPRAS in 1983. The initial crude-oil processing capacity of the refinery was 1.0 million t/year, which was increased to 5.5 million t/year in 1971 and 11.5 million t/year in 1985 by two major expansion projects. As of 2008, it processes 11.0 million t/year of crude-oil and holds 1.97 million $\mathrm{m}^{3}$ crude oil and product storage capacities. The refinery is one of the most enhanced refineries in the Mediterranean region with a Nelson complexity index (NCI) of 7.78 (TUPRAS, 2009). $\mathrm{NCI}$, which provides insight into refinery complexity, replacement costs and the relative value addition ability, is 1.0 for crude distillation, about 5.0 for cracking refineries, and over 9.0 for coking refineries (Reliance Industries, 2011).

The refinery was the industrial facility that suffered the most damage in the Kocaeli earthquake. Besides extensive structural damage to processing, storage and utility units, there were concurrent natech events at different parts of the refinery (Steinberg et al., 2001; Görgün, 2007). The collapse of a stack initiated a fire at the crude-oil unit, while sparks created by the bouncing of floating roofs ignited another fire at the naphtha tank farm. Fire fighting activities were hindered by the damage to the utilities and limited resources due to the earthquake. The vicinity of the refinery had to be evacuated, which prevented search and rescue operations from the debris. The fire at the tank farm lasted for 5 days and could only be extinguished with international response efforts. Furthermore, the spill of oil products caused considerable sea pollution.

A detailed description of the incident is presented in the following sections, which are mainly based on first hand information obtained from HSE managers of the TUPRAS Izmit refinery during a site visit in April 2010. Interviewed managers had been present in the refinery during the natech event and actively participated in the response and remediation activities. The information is supplemented by data from articles and technical reports, which are cited separately.

\subsection{Description of the event}

Shortly after the earthquake, fires started simultaneously at three different locations in the refinery. All units of the refinery were shut down to prevent further damage. Electricity was not available due to the failures in the national grid. The water supply was interrupted because of extensive damage to the pumping stations at the Sapanca Lake, from which all water needs of the refinery were met. The main water supply pipelines were destroyed by the earthquake as well. Hence, fire fighting activities were limited to on-site water storage, which was about $36000 \mathrm{~m}^{3}$. However, since the water storage tanks were not covered, a significant amount of water was lost due to the sloshing effect of the earthquake. In the absence of electricity, the water pumps could only be powered by diesel generators with considerably lower capacities. Under these conditions, the fire fighting teams together with all the personnel in the nightshift responded to the fires.

The first fire, which started in the chemical warehouse shortly after the earthquake, was of limited size. Materials stored on the shelves fell down due to the strong ground motion, glass containers were broken, and contents were spread onto the ground. The fire, which was ignited either by sparks or by exothermic chemical reactions, was extinguished in under half an hour.

The second fire started at the crude-oil processing plant (Plant-25), which had been constructed in 1982 and had a crude-oil processing capacity of 5 million t/year. One of the two stacks of the plant (Stack 25F-5), with a height of $115 \mathrm{~m}$ and a diameter of $10.5 \mathrm{~m}$, collapsed due to the earthquake. One fragment fell over the furnace of the plant and caused heavy damage. The other fragment fell over a pipe rack connecting the processing units to the storage tanks, breaking 63 product and utility pipes. The fire, which started when the highly flammable substances found in the pipes ignited, was extinguished in $4 \mathrm{~h}$ before 07:30 LT. However, the fire flared up again at noon because of a continued fuel supply from the broken pipes connected to the burning naphtha tanks in the tank farm. Block valves were located close to the tanks and hence inaccessible due to the fire, which in turn made it difficult to control the fuel flow (Johnson et al., 2000). Fire fighting efforts continued until the evening and the fire was extinguished completely at 18:15 LT.

The third and the largest fire occurred at the naphtha tank farm, which is located approximately at the center of the tank farm area of the refinery. Four medium-sized floating roof naphtha storage tanks were ignited following the earthquake by sparking due to the bouncing of the floating roofs against the inner side of the tanks and subsequent metal-tometal contact between the metallic seals and the tank walls. During the first phase of the fire, fire fighting teams were successful in controlling the flames with the limited resources that had to be distributed between Plant-25 and the naphtha tank farm fires. As shown in Fig. 1a, which was taken $7 \mathrm{~h}$ after the start of the fire, the fires at two tanks (in the center, 


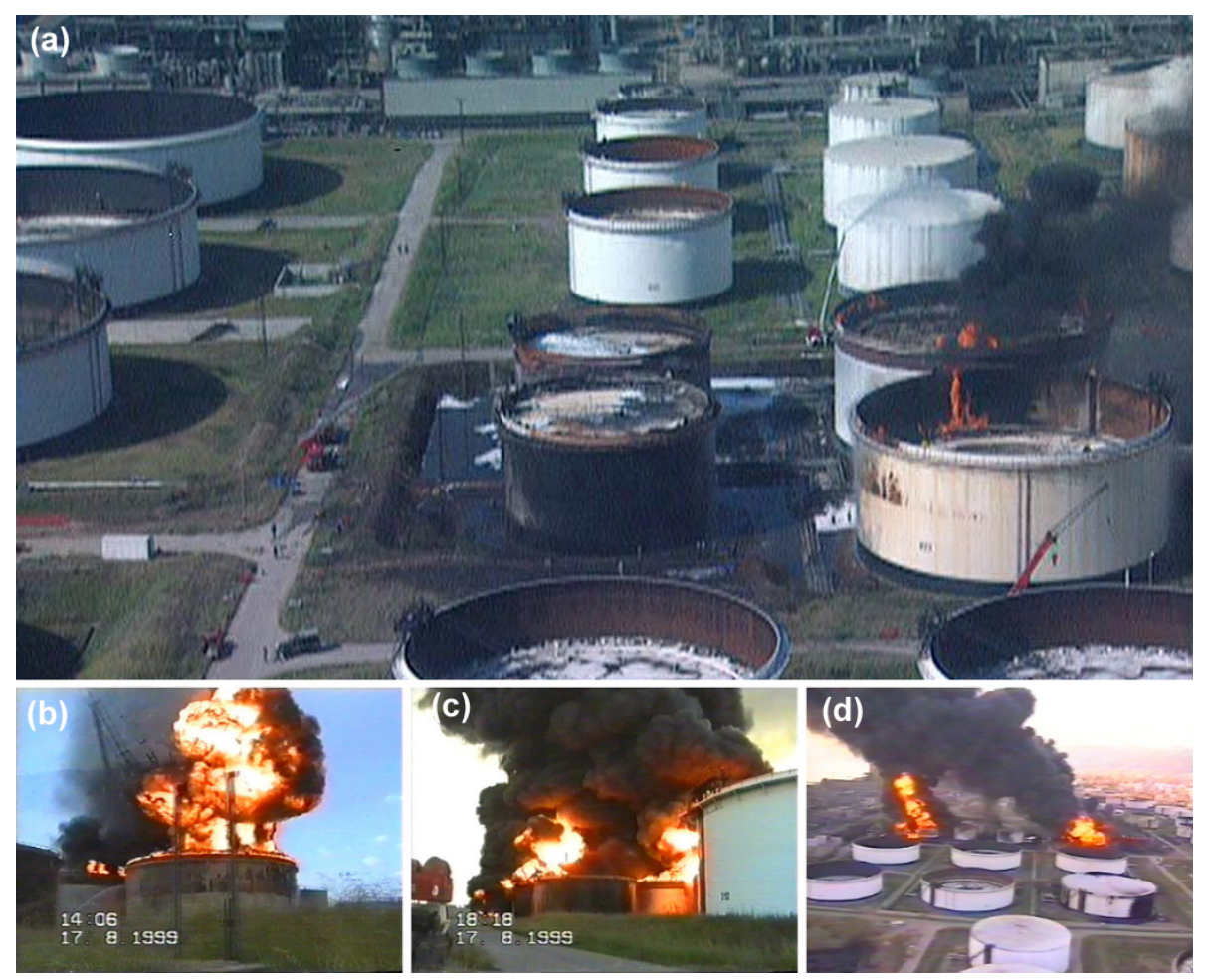

Fig. 1. The progress of the tank farm fire after the flange failure.

TK-241 (in the back) and TK-242) were completely extinguished and the remaining two (on the right, TK-202 (in the back) and TK-203) were under control. Later on, the flange at the bottom of tank TK-202 failed, probably due to fatigue caused by the excessive heat and structural deformation due to the earthquake. Naphtha inside the tank started to flow outside through the flange; this led to a jet fire and flames covered the tanks. Roof fires started again as can be seen in Fig. $1 \mathrm{~b}(t=11 \mathrm{~h})$. The fire spread through an open ditch to the tank farm located south towards the processing units (Fig. 1c, $t=15 \mathrm{~h}$ ). Eight tanks from this tank farm are visible in Fig. 1a behind TK-241 and TK-202 in a $2 \times 4$ arrangement. In this section of the storage area, the first two tanks on the right (fixed roof) and on the left (floating roof) were storing heavy vacuum gas oil (HVGO) and heavy straightrun naphtha (HSRN), respectively. Although affected on the outside very badly by the fire impingement, these tanks were not ignited. But two small naphtha tanks (TK-221 (last) and TK-222) located behind the HSRN tanks were engulfed by the flames and burned completely. The spreading of the fire is evident in Fig. 1d, which is oriented in a north-south direction from the right to the left.

Despite additional support provided by the military, the municipalities and neighboring facilities, the fire fighting teams lost control of the fire due to the major conflagration and had to retreat. Diesel pumps and the pumps of towing boats were utilized to supply water from the sea, but the ef- fort remained insufficient. Lack of electricity and shortage of foam hampered the response activities, as well. Forest fire and carrier airplanes responded to the fire by throwing sea water and foam on it from the air. However, they could not effectively control the fire since it was not possible to fly low enough to approach it. Being in a desperate situation, the fire fighting operations were abandoned at 19:00 LT $(t=16 \mathrm{~h})$. An evacuation order was issued by the crisis center for a zone of $5 \mathrm{~km}$ around the refinery and the government requested international assistance. The next day, a barrier was constructed between the burning naphtha tank farm and the LPG tanks to prevent the fire from reaching that part of the refinery and causing a boiling liquid expanding vapor explosion (BLEVE), which occurs when a vessel containing a pressurized liquid above its boiling point is ruptured, releasing the contents explosively. The tanks were cooled both from the air and the ground as well. National and international aircraft, including helicopters, continued the fire fighting efforts from the air. Meanwhile, electricity was restored to the water pumps at Sapanca Lake and water started to be pumped to the refinery in the evening hours. In response to the international aid request, a foam supply, fire fighting aircraft, fire experts, fire fighting vehicles and personnel were sent by several countries. In particular, fire fighting teams from Azerbaijan (10 firefighters specially trained for refinery fires), Bulgaria (6 fire fighting vehicles and 30 staff members), and Germany (portable water pumps and staff) participated actively in the 
fighting of the fire and their courage and efforts were highly appreciated (Yeletays1, 2007). On the third day, the fire fighting activities accelerated when water from the main line became available again. While foam spraying and cooling activities were continued by the aircraft, an extensive counterattack involving all teams was organized on the ground from all sides of the burning tanks. After serious efforts, the fire was put under control and all tanks except TK-242, which was left to burn in a controlled manner, were extinguished on 20 August. Consequently, force majeure status of the refinery was reduced to emergency level. The fire at TK-242 was finally extinguished on the next day (Görgün, 2007).

\subsection{Consequences}

Due to the collapsed stack and the subsequent fire, one crudeoil processing plant (Plant-25) and a pipe rack were heavily damaged. Post-event examination and modeling studies revealed that the collapse of the stack was not due to lack of strength caused by design or material deficiencies but due to the presence of reinforcing-bar splices in the region where flexural yielding occurred (Kilic and Sozen, 2003). During the massive naphtha tank farm fire, 6 naphtha tanks and $30500 \mathrm{t}$ of the product were burned completely. Five additional storage tanks were heavily damaged by fire impingement. One wooden cooling tower located close to the burned naphtha tanks was burned as well (Danış and Görgün, 2005). The fire affected neither the crude oil, gasoline, and LPG tanks of the refinery, nor the ammonia storage tanks of the fertilizer plant located next to the refinery. Hence, no off-site domino effect beyond the refinery boundaries, which was indicated as probable when the fire was left unattended, happened. There were no fatalities or injuries during the fire fighting. Train services connecting Ankara and Istanbul were disrupted because of the fire.

Besides the fires, considerable structural damage occurred to port facilities, storage tanks, cooling towers, and utility lines, although no significant ground failure occurred at the refinery during the earthquake except for some minimal liquefaction of the reclaimed land. The majority of the floating roof tanks (30 out of 45) were damaged due to liquid sloshing, resulting in $250000 \mathrm{~m}^{3}$ crude oil and $100000 \mathrm{~m}^{3}$ oil product having been exposed to the atmosphere and partially pouring out of the tanks. The roofs of 5 crude-oil tanks were completely submerged (Görgün, 2007). The damaged tanks were vulnerable to fire due to flammable vapors rising from the damaged roofs, but thankfully, such an accident did not happen. Other failure modes observed at the tank farm were cracking of tank roof-shell wall joints, bulging of tank tops, and elephant-foot buckling (Steinberg et al., 2001). Although the tanks were not anchored, no significant sliding was observed and hard piping performed well (Sezen and Whittaker, 2006). The reinforced concrete bearing columns of a $3000 \mathrm{~m}^{3}$ capacity LPG tank were damaged. One of the wooden cooling towers slid for $4 \mathrm{~m}$ and collapsed completely. Pipelines transporting crude oil from tankers to the storage tanks and located at the shoreline fell from the concrete embankment towards the seaside, but they did not rupture. However, the loading and unloading jetty was damaged heavily (Johnson et al., 2000).

Considerable oil pollution occurred during the incident. Shortly after the earthquake, some oil spilled into the sea due to fracturing of pipes and from an oil tanker that pulled away from the loading jetty immediately (Johnson et al., 2000). However, the main reason for the sea pollution were the fire fighting efforts themselves. During the fire fighting operations, large quantities of oily water began to flow out of the embankments surrounding the tanks, spilled into the water drainage system, flooded the wastewater treatment plant, and subsequently flowed into the Izmit Bay. As an immediate response and within $3 \mathrm{~h}$ from the earthquake, barriers were put into the sea. However, because priority had been given to the fires in the refinery, an effective response could not be achieved. On 20 August, a special response team from the Oil Spill Response Limited (OSRL) arrived at the refinery to undertake oil spill response and clean-up activities. Over $500 \mathrm{~m}^{3}$ oil was collected from the separator of the wastewater treatment plant. About $400 \mathrm{~m}^{3}$ emulsified oil that had been reported at two harbours located west of the refinery, Tavsancil and Karamursel, was recovered during a 6-day clean-up operation. An additional $32 \mathrm{~m}^{3}$ material was recovered from the beach adjacent to the refinery (Harmer, 2001). Okay et al. (2001) reported that polycyclic aromatic hydrocarbon $(\mathrm{PAH})$ concentrations in the seawater, sediment and mussels had increased in Izmit Bay after the incident. PAH concentrations in seawater both at offshore and coastal sites were about $2 \mu \mathrm{g} / \mathrm{l}$ in April 1999, but increased to 3.5-11 $\mu \mathrm{g} / \mathrm{l}$ and $5-17.5 \mu \mathrm{g} / \mathrm{l}$ at offshore and coastal stations, respectively. Furthermore, a two to three fold increase in sediment PAH concentrations was detected, especially around the refinery.

The majority of the units, which were out of service due to the earthquake and fire damage, were put into operation within less than 3 months after the earthquake when the refinery became functional again. Following about 200 maintenance and restoration works, which were completed earlier than planned, all units were operational after one year. During the restoration period the demand for oil products was met by additional import and increased production capacities of other refineries including the ATAS refinery in Mersin, which was the only refinery not belonging to TUPRAS at that time. It was converted into a storage facility in 2004. The total cost of restoration, including the oil spill clean-up, was 57.8 million USD, which is half of the initial estimate of 115.0 million USD. $95 \%$ of this loss was covered by the insurance (Danış and Görgün, 2005). The operational loss of the refinery can be seen in Fig. 2, which shows the amount of crude-oil processed by TUPRAS refineries between 19962003. The refinery's loss of production due to the earthquake is evident from the sharp decrease in the processing, while the other refineries have a steady trend. By taking the average 


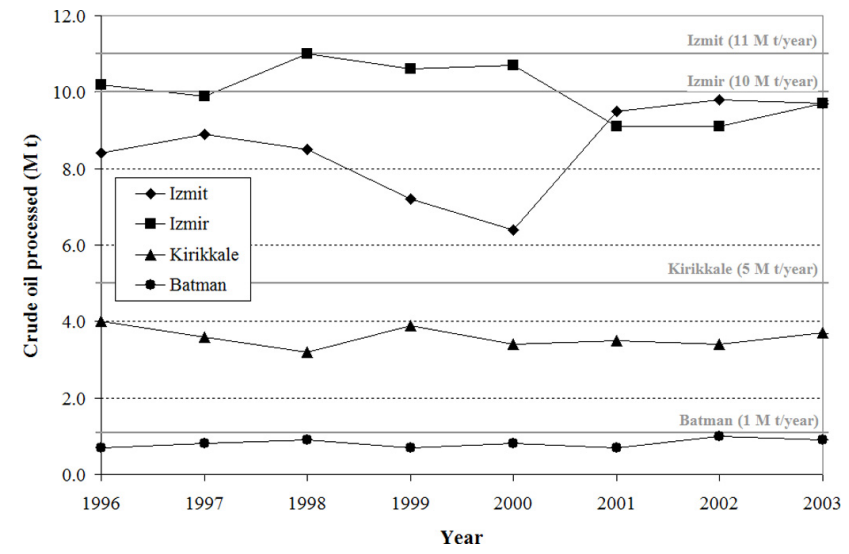

Fig. 2. Yearly distribution of crude-oil processed by TUPRAS refineries.

of crude-oil processing values before 1999 and after 2000, the expected crude-oil processing value if the natech would not have happened is found to be 9.1 million t/year. Based on this value, the total loss of crude-oil processing capacity of the refinery is 4.6 million $t$ during the recovery period. This value is roughly equivalent to 6 months of production loss and confirms the initial estimate for the operational losses made just after the earthquake (Hürriyet, 1999c).

\subsection{Restoration and follow-up}

TUPRAS was criticized for not being sufficiently prepared for such a natech event, although it was known that the refinery is located in a high earthquake risk area. The criticism mainly focused on the lack of foaming systems on the tanks, inadequate diesel pumps, the limited application of sprinkler systems, non-interoperable firewater connections, insufficient containment ponds, the lack of fire fighting towers, and deficiencies in the coordination and management of the fire fighting activities (Kıliç, 1999).

In fact, the 1999 Kocaeli earthquake was not the first time for the refinery to experience an earthquake-triggered natech. After the 1967 Mudurnu Valley earthquake (22 July $1967, M_{\mathrm{S}}=7.1$ ), a major fire was ignited in the crude-oil processing unit and was extinguished by the refinery personnel (Bortaçina, 1999). The epicenter of the 1967 Mudurnu Valley earthquake was near Akyazi about $80 \mathrm{~km}$ east of the refinery and had an intensity of MCS VIII-IX (Ambraseys, 1968). Since the refinery was located far away from the epicenter and operating at its initial capacity, damage was limited and it is quite likely that the experience was forgotten in over 30 years from then until 1999.

The seismicity and the earthquake risk of the refinery were assessed in a study in 1976, before the second major expansion. Based on the average annual occurrence curve of the earthquakes in the vicinity of Izmit, the return period of a 7.5-magnitude earthquake was found to be 125 years. As-

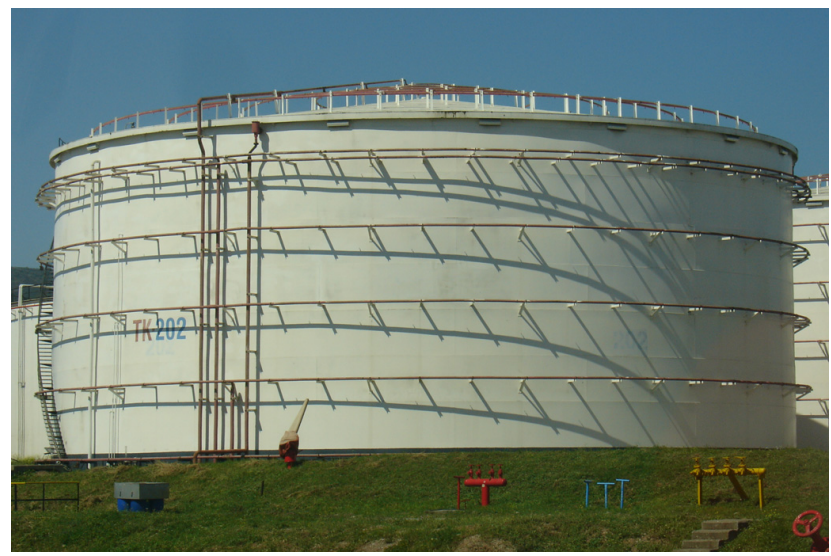

Fig. 3. Retrofitting on the naphtha tank TK-202 burned during the fire.

suming the lifetime of the tanks to be constructed in the tank farm as 50 years, the expected maximum earthquake magnitude was calculated as 6.5-7.0. The duration of a probable earthquake was estimated as $20-25 \mathrm{~s}$ and no liquefaction or ground collapse were expected (Danış and Görgün, 2005). The 1999 Kocaeli earthquake showed that these estimates were not accurate. The overall seismic risks of the TUPRAS refineries were re-assessed by detailed field investigations and the structural analysis of critical components and structures, such as storage tanks, stacks, chimneys and frame structures. Seismically vulnerable components were identified and proactive seismic upgrades were applied to reduce the risk. Emergency response plans were reviewed; fire and oil-spill fighting capacities were increased drastically (Görgün, 2007).

The burned naphtha tanks were floating-roof tanks with a single line of sprinklers at the top. They were reconstructed in the form of internal floating-roof tanks with advanced sprinkler systems around and over the tanks. Water cannons and foaming systems having in-situ foam stocks were installed next to each tank. The number of fire fighting hydrants was increased and converters were provided to improve the interoperability of internal and external fire fighting equipment. Embankments around the tanks were reinforced to prevent leakage to other sites in case of overflow. Improvements made at the tanks are illustrated in Fig. 3, where the retrofitted TK-202 is shown. Compared to the old tank shown in Fig. 1a, significant progress is evident. The resilience of the other tanks in the tank farm was also improved, although not to the same level as the naphtha tanks. Sprinkler systems were upgraded and foaming systems were implemented. Fifty fixed and 10 portable water cannons were installed. The bearing columns of spherical LPG tanks were reinforced. Gas and flame detectors were installed at the tanks and in the processing units. The water capacity for fire fighting was increased 5 fold and the fire water network within the refinery was enhanced. In order to make use of the sea 
Table 1. Selected safety and fire fighting system improvements at the refinery.

\begin{tabular}{ll}
\hline Problem & Precautionary measure \\
\hline Insufficient preparedness for natechs & Revised emergency response plan taking natechs into consideration \\
Inadequate response to the natechs & Disaster management plan with scenarios: \\
& - Fire events at four different locations \\
& - Fire at the largest storage tank with minimal water supply \\
Deficiencies in coordination and man- & Bimonthly emergency response practices based on probable scenarios including \\
agement of response activities & natechs with participation of all refinery personnel \\
Inadequate fire water supply & Increased fire water capacity (5 folds) \\
Ineffective use of sea water & Portable diesel water pump $\left(900 \mathrm{~m}^{3} / \mathrm{h}\right)$, monitor and $6^{\prime \prime}$ hose $(2 \mathrm{~km})$ \\
& Sea water connection to fire water system \\
Lack of sprinkler and foaming systems & Water sprinkler and foaming systems at all tanks \\
& Gas and flame sensors \\
Insufficient fire fighting equipment & Upgrade of the fire water network \\
& Upgrade of fire fighting vehicles \\
& Water canons ( 50 fixed and 10 portable) \\
Insufficient oil spill response & Increased oil barrier stock $(3 \mathrm{~km})$ \\
& OSRL membership \\
\hline
\end{tabular}

water more efficiently, powerful portable diesel pumps were added to the inventory. Hoses of sufficient length to reach the units and the storage tanks located in distant parts of the refinery were supplied. Buildings were retrofitted according to the 1998 Turkish specifications for structures built in disaster areas, which include modern earthquake provisions (Official Journal, 1998). On the management level, safety and fire fighting standards were improved. Based on the lessons learned during the management and coordination of the response activities, a disaster management plan was prepared in 2000 to improve the efficiency in first response and the mitigation of consequences. The current disaster management plan considers two natech scenarios. In the first scenario, a fire in one of the largest storage tanks, about $135 \mathrm{~m}$ in diameter and located at a remote site, is speculated to have limited fire fighting water resources. The second scenario is based on 4 fires ignited concurrently at different locations within the refinery. Finally, a membership agreement was signed with OSRL for quick response to oil spills, both on land and offshore (Görgün, 2007). A summary of the measures applied at the refinery after the Kocaeli earthquake is given in Table 1 together with the reasons for these actions.

\section{AKSA acrylonitrile spill}

Aksa Acrylic Chemical Industry Corp. (AKSA) is an acrylic fiber production facility located on the southern coast of the Izmit Bay, $20 \mathrm{~km}$ west of Yalova. Constructed in 1968, the facility had an initial production capacity of 5000 t/year in 1971 , which was gradually increased and reached $230000 \mathrm{t}$ /year in 1999 and $308000 \mathrm{t}$ /year in 2008. Currently it is the only producer in Turkey and the largest in the world with a global market share of $12.5 \%$ (AKSA, 2009).
For the production of acrylic fiber, acrylonitrile (AN) is used as the raw material and is stored in large quantities at the facility. AN (CAS: 107-13-1) is a hazardous chemical that is highly flammable, toxic, hazardous to aquatic environment, and may cause cancer (European Union, 2008). The International Agency for Research on Cancer classifies it as possibly carcinogenic to humans with sufficient evidence for carcinogenicity in experimental animals (IARC, 1999).

The earthquake damaged three of the storage tanks at AKSA and caused about $6500 \mathrm{t}$ of AN to be released into air, sea and groundwater. All animals and vegetation died inside the facility within a $200 \mathrm{~m}$ radius around the tanks. Acute toxicity symptoms were observed in the emergency response teams and the public living in the vicinity. According to Voice of Yalova (2010), there is an alleged increase in the cancer rate due to the event.

\subsection{Description of the event}

Out of six acrylonitrile storage tanks located in the facility, one was empty and the remaining five were partially filled before the earthquake. Three of the filled tanks were damaged. On one tank the roof ruptured, whereas the other two suffered pipe breaking at their base. Approximately $6500 \mathrm{t}$ of AN was released into the concrete containment dikes around the tanks with base damage and to the atmosphere from the tank with roof damage. A significant amount of the spilled liquid AN overflowed from the containment dikes and was lost into the sea as surface runoff through the drainage channel. A portion of the remaining AN evaporated into the atmosphere. Due to the cracks created by the earthquake at the bottom of the concrete containment dikes, a considerable amount of the AN leaked into the soil and subsequently reached the underlying shallow coastal aquifer at the site (Şengör, 2002). 
Electricity was not available and all water pipes, including the ones used for fire fighting, were broken, causing $400 \mathrm{t}$ of water in the water storage tank to flow into the sea (Bayer, 1999). The vapor suppression system installed to contain accidental spills could not be operated properly due to the loss of water pressure. The emergency generator of the plant, which was located close to the storage tanks, could not be operated since it was not explosion proof and the concentration of highly flammable AN was very high in the air (Steinberg and Cruz, 2004). Hence, special foam to prevent the evaporation of AN had to be applied manually during the initial response. Once the generator was moved to a safe distance, it was used to pump sea water for foam generation.

Around 13:30 LT, the crisis center of Yalova was informed about the spill. The general manager of the facility urgently requested special foam, sprays, pumps, and gas mask filters, which were insufficient in the facility, and he stated that an area of $6 \mathrm{~km}$ radius around the facility should be evacuated due to the risk to the public health. Although there was awareness that the rescue operations would be hampered, the evacuation order was inevitably issued by the crisis center considering the seriousness of the situation. Since there were no means of telecommunication, the public was informed personally by the local security forces, and settlements were started to be evacuated from 15:00 LT on (Ekim, 2003). Also towns which were more than $10 \mathrm{~km}$ away from the facility were reportedly evacuated (Kaplan, 1999).

In reply to an external support request, the fire fighting team of the nearby military airport joined the mitigation operations. Fire brigades of nearby municipalities and Istanbul supplied foam and pumps, but did not join onsite activities because the working environment was highly toxic and protective measures, such as gas masks and airtight suits, were lacking (Şenocaklı, 2003a). Barriers were constructed to prevent surface runoff of the AN to the sea. After the electricity was recovered at $t=36 \mathrm{~h}$, AN was started to be transferred from the containment dikes into intact tanks and the wastewater treatment pond. About $3000 \mathrm{t}$ of AN were reported to have been collected in this way (Şengör, 2002). Emergency response activities continued for more than one week until all spilled material was transferred to safe tanks and evaporation was prevented. During the transfer operation, atmospheric AN concentrations of $360 \mathrm{ppm}$ were measured in the vicinity of the pump and 10-30 ppm at other locations within the facility (Supreme Court, 2004).

\subsection{Consequences}

Despite AN being highly flammable, no fire occurred during the incident. During the initial response, 27 workers were reported to have been poisoned (Hürriyet, 1999b). One member of the military fire fighting team reportedly went into a coma, while the others were affected badly (Supreme Court, 2004). All the animals located in the zoological garden of the facility and vegetation, including plants and pine trees, died within $200 \mathrm{~m}$ distance from the leaking storage tanks. Birds and domestic animals were also reported to have died in the settlements close to the facility (Kaplan, 1999). Many fish kills were reported due to the AN spilled into Izmit Bay through the drainage channel (Türk, 1999). The measurements conducted at three sampling stations close to the facility showed that AN concentration in the seawater was $0.157-2.88 \mu \mathrm{g} / \mathrm{l} 10$ days after the incident, which decreased to $0.075-0.178 \mu \mathrm{g} / \mathrm{l}$ after 25 days. Acrylamide, which is a hydrolysis product of $\mathrm{AN}$ in the aquatic environment, was also found in the samples (Güven and Gezgin, 2005). Acrylamide (CAS: 79-06-1) is known to be toxic, carcinogenic, mutagenic, and toxic for reproduction (European Union, 2008).

Inhabitants of settlements in the vicinity of the facility suffered symptoms of acute toxicity, such as hoarseness, vertigo, nausea, respiratory problems, skin irritation, headache, eye and nasal irritation (Şenocakl1, 2003b; Aydemir, 2010b). These health problems also hampered search and rescue operations, which were mainly conducted by the local people due to lack of professional search and rescue teams. Following the evacuation order, the settlements were started to be evacuated, but exposures up to $20 \mathrm{~h}$ were reported (Aydemir, 2010b). Due to the natural hazard conditions, the local hospitals and clinics were overcrowded with seriously injured people. Hence, they were not able to respond properly to the poisoned people and treat the symptoms adequately (Hürtaş, 1999). Lack of communication also prevented health officials from receiving information about the properties of AN and treatment methods of its toxic effects from the experts of the facility. A public health survey conducted by the Istanbul Chamber of Medicine two months after the incident and covering 149 residents of the closest settlements to the facility, namely Altinkum, Basak and Taskopru, revealed that acute toxicity effects were observed in the majority of the survey participants from Altinkum (Fig. 4). Toxicity effects were observed to a lesser extent among the residents of Basak and Taskopru with increasing distance to the facility (Emiroğlu et al., 2000). Altinkum is located $650 \mathrm{~m} \mathrm{NW}$ of the tank farm, within the $1200 \mathrm{~m}$ health protection zone of the facility, whereas Basak and Taskopru are situated about 2 and $2.5 \mathrm{~km} \mathrm{SW}$, respectively. Long-term health statistics are not available, hence the long-term health impacts are not known. But it was reported that among the 189 people who prosecuted the company after the incident, 17 had died from cancer and 5 additional are being treated for cancer (Aydemir, 2010a). Among the 5 members of the military fire fighting team, which responded to the spill in the first days of the incident, one reportedly died of lung cancer and another one is being treated for it (Hürtaş, 2009).

After they had been informed that the danger had been passed, evacuees returned to their villages from 24 August onwards. Agricultural activities were resumed in the farms located around the facility. It was reported that the harvested products, which were contaminated with $\mathrm{AN}$, were put on the market and sent as far as Istanbul for a couple of days 


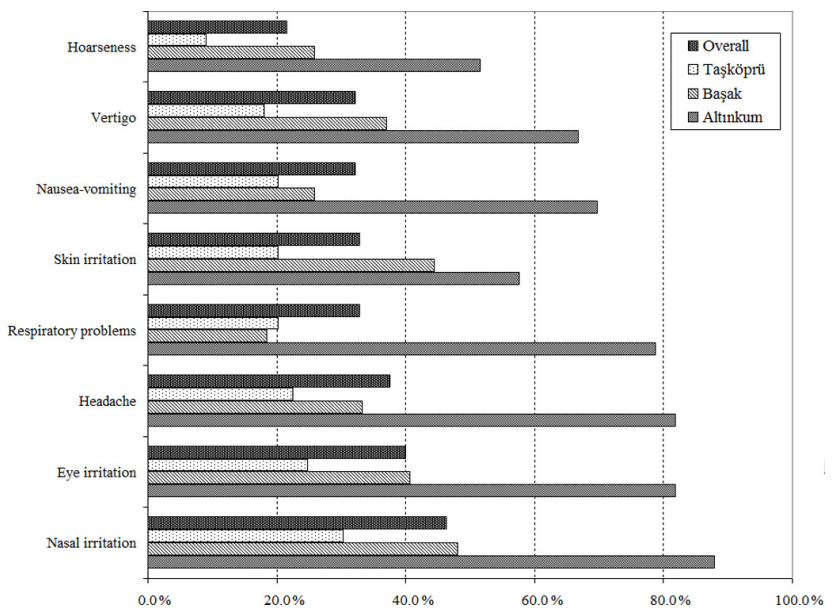

Fig. 4. The distribution of the symptoms of toxic exposure by settlements.

until a ban was issued by the local government (Kaplan, 1999). After the ban, the produce of the farms located close to the plant was collected and subsequently destroyed. Production losses were reimbursed by the company, which was afterwards compensated by its insurance (Şenocakl1, 2003c; Supreme Court, 2004).

\subsection{Restoration and follow-up}

An extensive ground water pump-and-treat system for hydraulic control and product recovery was initiated after the incident. Eleven monitoring wells were constructed in order to determine the extent of groundwater pollution. Utilizing 5 additionally existing boreholes, AN concentration, $\mathrm{pH}$, electrical conductivity and groundwater level measurements were started at 16 locations within the facility area in September 1999. Based on monitoring data, two pumping wells were installed inside the damaged tank dike and four French drain-type drainage trenches were gradually put into operation around the tank farm (Şengör, 2002). During the first year of the operation, the extracted ground water was treated by an on-site distillation unit and over $80 \mathrm{t}$ of AN were recovered (Parametrix, 2002). Afterwards the groundwater was treated in the wastewater treatment plant of the facility to recover the low levels of AN, which could not be efficiently recovered by distillation. In order to optimize this clean-up performance, the groundwater extraction scheme was continuously altered by switching pumping on and off at different pumps and drainage trenches according to measurements of the AN concentration, groundwater level and rainfall. At the end of the third year, the AN concentration had decreased from its initial level of $>80000 \mathrm{mg} / \mathrm{l}$ to non-detectable levels and stabilized. The pump-and-treat operation was continued for five years, resulting in the treatment of $53000 \mathrm{~m}^{3}$ of groundwater. Monitoring studies were maintained for two more years until September 2006 (Zanbak, 2008).
As part of the restoration work, all storage tanks were strengthened against sloshing effects and secondary roofs were constructed to minimize evaporation in case of a leak. Hard piping connections to the storage tanks were replaced with flexible connections (Ekimci, 2000). The ground of the containment dikes was covered with impermeable material and the dikes were reinforced. Foaming sprays were installed around the tanks. Underground water pipes that were broken during the earthquake were installed over ground. The capacity of emergency power generators was increased and additional pumps were installed. Emergency response plans were reviewed and improved by taking natech scenarios into account.

The company was prosecuted by about 200 people and over 40 lawsuits were filed both for punishment and compensation. The suits of punishment for the harm to human health and the environment were annulled in 2003, because of the death of the general manager of the facility who claimed responsibility in the name of the company. The suits of compensation continued for 9 years. The local civil court decided in favor of the defendant several times, but the judgments were reversed on appeal by the supreme court (Zaman, 2005; Sabah, 2006). In the end, the company was fined for monetary compensation. As of 2010, the trials are still continuing at the European Court of Human Rights (Aydemir, 2010a).

\section{Discussions}

Both the TUPRAS and AKSA incidents show that the loss of electricity and an insufficient water supply were important factors aggravating the natech events during the earthquake. In fact, the fire fighting and emergency response infrastructures were designed and built under the assumption of robust power and material supply, relying on external (e.g. national interconnected network) or internal (e.g. power regeneration plant) resources. Both types of resources failed during the earthquake and are likely to fail during natural hazards. An extensive study in the region performed by Steinberg and Cruz (2004) showed that the most common failures at 19 visited industrial facilities affected by the earthquake were loss of electricity, loss of water or water pressure, and lack of personnel (in all visited facilities), followed by structural damage (95\%), rupture of pipes and connections (63\%), and liquid sloshing (58\%). The analysis of the failures leading to or affecting the response to natech events reveals that the most significant factors are loss of electricity (74\%), liquid sloshing (47\%), and loss of water or water pressure (37\%). Hence, damage to utilities is a general and major problem during earthquake-triggered natechs.

Although emergency and back-up systems for electricity and water supply were available at TUPRAS and AKSA, they were inadequate to meet the needs of the emergency response activities. This situation was recognized at the highest level of administration and the general managers of the facilities admitted that they had not been prepared for the 
earthquake and the associated natech events (Bayer, 1999). Actually, the facilities did have environmental and health and safety management systems, and were known to be complying with national environmental and occupational health and safety regulations. Emergency response and mitigation plans were in force before the earthquake and the associated equipment and human resources were available. However, the facilities' emergency response performance was deficient because they were prepared for incidents expected to occur during the normal operation of the facilities. Natechs had not been taken into consideration while plans were prepared.

Considering natech hazards for planning purposes requires the development of credible natech scenarios which is not a simple task. A typical emergency response scenario is generally based on a single event deemed to be worst-case and it assumes the existence of sufficient response capacity. In complex scenarios, domino effects are considered and some response or mitigation measures are presumed to be unavailable. Such plans result in the allocation of additional response capacity, increased self-sufficiency, and backup mitigation systems. However, realistic natech scenarios require concurrent multiple events to be considered under disaster conditions, whereby the majority of mitigation measures are lacking. As the number of simultaneous events increases and the availability of the response capabilities decreases, the scenarios become more and more difficult to cope with and require serious emergency-response investment. Clearly, it is not reasonable and also possible to backup every utility and keep fire fighting material sufficient to extinguish a conflagration of the whole facility in stock. For industry, it is important to balance the level of safety and its cost. Large industrial facilities, like TUPRAS or AKSA, are capable of covering the cost of a high level of safety and in fact, they did invest significantly in natech preparedness after the 1999 Kocaeli earthquake, as explained in the preceding sections. However, many industrial facilities prone to natechs, especially SMEs, have only limited resources that can be allocated for this purpose. In this respect, the development of credible, as well as applicable natech scenarios is very important. Scientific studies are rare and there is a lack of methodologies and guidelines on this topic, hence further action is required (Krausmann, 2010; Krausmann and Baranzini, 2009).

Emergency response plans that consider natech hazards should also be reviewed and updated periodically to take into account recent natural-hazard information and the status of the facility. It is common practice in the industry to construct a facility with a limited initial capacity and expand it in the following years according to the profit and market demand. This is especially the case in developing countries, where the investment resources are limited and the market is risky. The production capacity of the TUPRAS Izmit refinery increased 11 fold in the first 25 years and since then, the processing units are renovated periodically. The increase in the production capacity of AKSA is more than 60-fold in 40 years. Clearly, the emergency response capabilities of the facilities should be sustained and upgraded in line with the growth, and this includes safety management systems, human resources, training, and equipment. Besides the changes in the facilities, changes in the natural hazard risks should also be considered appropriately. During the lifetime of a facility, the natural hazard risks can vary drastically. An earthquake that would happen on a fault line could influence the earthquake occurrence probabilities all along the fault zone. Severe meteorological and hydro-meteorological natural hazards are predicted to increase with global climate change (van Aalst, 2006; IPCC, 2007); thus, their risk is also increasing. Such changes should be considered in natech risk management.

As is the case in many other countries, the existence of settlements close to industrial facilities increases the risk of natechs. In Turkey, industrial facilities posing considerable health and safety risks are required to be located distant from settlements by law since 1930 (Official Journal, 1930). Several regulations have been published to date to list such industrial activities and arrange provisions required for permit procedures. According to these regulations, health protection zones, where settlements are forbidden, should be designated around the hazardous installations. The size of a health protection zone is designated case by case by a local committee composed of administrative and technical staff. Municipal plans controlling development and settlement have been relied on for the maintenance of the designated zones. Although the regulations were in force before the start of the industrialization period of the country in the late 1960s, appropriate safety distances do not always exist between the settlements and the industrial facilities as in the case of AKSA. AKSA has a health protection zone of $1200 \mathrm{~m}$. This zone was designated 20 years following the construction of the facility and there were housings and farms within the zone, which were built before this date (Kaplan, 1999; Supreme Court, 2004). After the designation of the zone, no additional development was allowed within the zone, but existing buildings remained as is and continued to be inhabited. These settlements and farms were affected intensively by the natech event.

In the TUPRAS case, the proximity of other industrial facilities storing hazardous substances to the refinery increased the risk of domino effects and affected the response activities. One of the reasons for evacuating when the conflagration in the naphtha tank farm went out of control, was the fear of the explosion of the ammonia storage tanks of the fertilizer plant located next to the refinery, which, if it had happened, would have been a catastrophe (Hürriyet, 1999a). On the other hand, the staff of the fertilizer plant had to evacuate their facility and before leaving, they opened the valves on the refrigerated ammonia tanks to prevent an intolerable build-up of pressure in the tanks as the ammonia warmed. This resulted in a considerable amount of ammonia being released into the environment (Steinberg et al., 2001). 
Both the AKSA and TUPRAS incidents highlight the importance of land use planning in mitigating natech consequences. For Turkey, inadequate health protection zones exist mainly due to various shortcomings in the development and enforcement of land use plans and this is partly a consequence of deficiencies in regulations. Upgrades in the existing facilities and the corresponding need for an increase in health protection zone distances have not been properly addressed in the regulations. In addition, it was unclear what should be done with illegal housing that was built within the zones after the construction of the facility. The most recent regulation published in 2005 aims to solve this problem by requiring the land within health protection zones to be owned by the industrial facilities (Official Journal, 2005). However problems with existing facilities seem to persist. The development of guidelines for the designation of health protection zones that take natechs into account is also important for supporting local technical committees in defining safe and standardized protection zones in a scientific manner.

In both the TUPRAS and AKSA incidents, the natech events resulted in the evacuation of nearby towns and hampered rescue activities. Evacuation seems to be inevitable in the case of major natechs, where the risk to the public and the first responders outweighs reaching the potential survivors still buried under the debris in a timely manner. However, limited awareness, misinformation, and inadequate communication through unofficial channels together with chaotic conditions due to the natural disaster may lead to the evacuation of areas where it would actually not be needed. In both natech incidents, settlements much further then the officially announced evacuation distances were evacuated by the public, due to limited information and the growing fear. In order to prevent this, evacuation plans should be prepared for natech-prone areas that take natech scenarios and their probable consequences into consideration. These plans should be practiced by the authorities and the public.

On the other hand, rescue operations may result in prolonged exposure of first responders and the public to hazardous substances, which may have adverse effects in the long term. In the AKSA incident, the acute toxicity effects of AN were noticed by the people living in the vicinity already shortly after the releases occurred. However, because there were survivors under the debris who were relatives and close friends, the people did not leave the place and continued rescue operations until the symptoms became too serious (Şenocakl1, 2003b; Aydemir, 2010b). During this period the evacuation order was not issued yet, hence people in the affected zones were not forced to leave their places. This situation is likely to occur for similar natechs involving toxic substances with acute and chronic health hazards. The public living in the vicinity of natech prone facilities should be informed about the properties of the hazardous substances stored or processed at the facility, their health impacts, the symptoms of the various toxicity levels, how to mitigate these symptoms and the duration of exposure deemed safe and during which the rescue operations could be continued. Prolonged exposure may be inevitable, but at least individuals can make an informed decision on how to act.

Although the majority of the hazardous industrial facilities has well-trained medical units to respond to emergencies, in the case of off-site consequences local hospitals and clinics have to treat people affected by hazardous substances. As it became apparent from the problems in the AKSA case, prior knowledge of the names and properties of substances, as well as of the symptoms of toxic exposure and the corresponding treatment methods may play an important role during the initial phases of the response activities. This is especially the case for natechs, in which there are many other hospitalized people taking precedence, human and treatment resources are limited, and communication is inadequate. Local medical services should be informed about the risks at industrial facilities and have adequate and appropriate medicine in stock for treating exposure to hazardous substances. Similar to the medical units, local security forces, such as the gendarmerie and military, play an important role during emergencies. In both the TUPRAS and AKSA incidents, they participated actively in the emergency response activities. Moreover, they were in charge of informing and assisting the public during the evacuation, and of securing the evacuation zones. Therefore, they were also exposed to the hazardous effects of natechs, although they are not professionals in the field and therefore have limited information about the risks. Proper training of local security units in the vicinity of natech-prone industrial facilities could be very beneficial for efficient natech emergency management.

\section{Conclusions}

The 1999 Kocaeli earthquake was the most destructive natural hazard that has happened in Turkey in the last decades. Besides enormous property damage and human losses, its effects on the economy and industry were also devastating since it occurred in one of the most industrialized regions of the country. Many industrial facilities had to cope with not only the structural damage, but also with secondary natech events triggered by the earthquake. The massive fire at the TUPRAS Izmit refinery and the hazardous AN spill at the AKSA acrylic fiber production plant were two natech events that attracted special interest due to their extent and consequences. As described in detail in this study, significant lessons can be learned from these events, which may subsequently lead to the proper consideration of natural hazards in emergency-response planning activities, the reduction of deficiencies in emergency management practices, and strengthening of design and construction standards at industrial facilities dealing with hazardous substances in natural-hazard prone areas.

As shown for the TUPRAS and AKSA cases, the preparedness of industrial facilities for natech events is currently 
high in facilities that have recently experienced natechs. However, natech preparedness is low in the majority of facilities, mainly due to economical reasons and because of regulations that do not sufficiently address natech hazards. Laws and regulation on land use planning, occupational health and safety, fire protection, and environmental protection have been in force for several decades. Nonetheless, they are not sufficient for proper preparedness for and response to the natech events. The Turkish emergency and disaster management framework was recently restructured and the context was expanded to include natechs. But the framework still focuses on natural disasters, mainly earthquakes, and natechs are not addressed properly (Girgin, 2010). In order to control major industrial accidents, a new regulation based on the 96/82/EC (Seveso II) Directive of the European Union, was put into practice in 2010 (Official Journal, 2010). This is an important step, since prevention of and preparedness for industrial accidents forms the basis of natech risk management. However, the location of high-risk industrial facilities is currently not known in detail and the data required for risk assessment are lacking. Moreover, the information on natural hazards is limited for many natural hazard types as well. Methodologies for rapid regional natech risk assessment would be useful to determine baseline conditions.

As presented in this study, Turkey experienced serious natech events during the 1999 Kocaeli earthquake. There is also concern about future natechs due to the elevated natural hazard risks of the country. The expected probability of occurrence of a major earthquake in Istanbul, which is the industrial capital of the country with more than 12 million inhabitants, is high. Therefore, the risk of accompanying natechs which aggravate the damage due to the earthquake is not negligible. According to a recent probabilistic model, the probability of a $M \geq 7$ earthquake rupturing beneath the Sea of Marmara is $53 \pm 18 \%$ (35-70\%) for the period of 2004-2034 (Parsons, 2004). The current disaster prevention/mitigation plan for Istanbul considers a scenario in line with this model as the most probable scenario. According to this scenario, for a model earthquake of $M_{\mathrm{w}}=7.5$, the estimated number of deaths and severely injured is 73000 and 120000 , respectively, which is almost 4 times higher than that of the 1999 Kocaeli earthquake (JICA, 2002). Although natech hazards are still little known due to a lack of awareness, distribution of industrial facilities in Istanbul with respect to earthquake hazard zones shows that many facilities are located in highintensity zones (Durukal et al., 2008). Detailed natech risk analysis and mapping studies based on realistic natech scenarios are required to be able to assess the natech risk for this area and the possible consequences in the case of an earthquake. The level of preparedness for natechs in industry should also be assessed.

Acknowledgements. This study has been supported by the international post-doctoral research fellowship program of The Scientific and Technological Research Council of Turkey (TUBITAK). The author would like to thank the HSE managers and engineers of the TUPRAS Izmit refinery for detailed information provided during his site visit. Suggestions provided by Elisabeth Krausmann of the European Commission Joint Research Center are highly appreciated.

Edited by: E. Petrova

Reviewed by: A. M. Cruz Naranjo and another anonymous referee

\section{References}

AKSA: Annual report 2008, Istanbul, Turkey, 100 pp., 2009.

Ambraseys, N. N., Zátopek, A., Taşdemiroğlu, M., and Aytun, A.: The Mudurnu Valley (west Anatolia) earthquake of 22 July 1967, UNESCO, Paris, 136 pp., 1968.

Aydemir, A.: Relation of AKSA and Yalova - what happened in the past?, Yalova Environment Platform, available at: http: //www.yacep.org/haber/haber_detay.asp?haberID=56, access: 10 November 2010a.

Aydemir, A.: The fall, Bolge, available at: http://bolge.com.tr/ KoseYazilari/YaziDetay.aspx?YaziID=462, access: 10 November 2010b.

Bayer, Y.: What happened at Yalova AKSA?, Hürriyet, 5 September 1999.

Bortaçina, A.: Internal systems are sufficient, Milliyet, 20 August 1999.

Danış, H. and Görgün, M.: Marmara earthquake and TÜPRAŞ fire, in: Proceedings of Earthquake Symposium Kocaeli 2005, Kocaeli, Turkey, 23-25 March 2005, 1362-1369, 2005.

Durukal, E. and Erdik, M.: Physical and economic losses sustained by the industry in the 1999 Kocaeli, Turkey earthquake, Nat Hazards, 46, 153-178, 2008.

Durukal, E., Erdik, M., and Uçkan, E.: Earthquake risk to industry in Istanbul and its management, Nat. Hazards, 44, 199-212, 2008.

Ekim, A.: Witness report presented to the Yalova Law Court, Yalova, 2003.

Ekimci, B.: AKSA is under the magnifying glass, Milliyet, 7 February 2000.

Emiroğlu, C., Koşar, L., Karadağ, K., Abbasoğlu, S. and Başçıl, H. S.: AKSA reality, Turkish Journal of Occupational Health and Safety, 3, 12-14, 2000.

European Union: Regulation on classification, labelling and packaging of substances and mixtures, amending and repealing Directives 67/548/EEC and 1999/45/EC, and amending Regulation (EC) No 1907/2006, Official Journal of the European Union,L 353, 1-1355, 2008.

Girgin, S.: Natech management in Turkey, International Disaster and Risk Conference, Davos, Switzerland, 30 May-3 June 2010, 393, 2010.

Görgün, M.: Major industrial accidents happened in Körfez, Occupational Health and Safety Congress, Adana, Turkey, 20-21 April 2007.

Güven, K. C. and Gezgin, T.: Determination of acrylonitrile and detection of acrylamide in seawater by GS/MS, Acta Pharmaceutica Turcica, 47, 15-20, 2005.

Harmer, T.: Turkey-oil spill response following an earthquake, in: Proceedings of International Oil Spill Conference 2001, Florida, USA, 26-29 March 2001, 457-460, 2001. 
Hürriyet: Flames went out of control, 18 August 1999.

Hürriyet: 27 workers were poisoned from the gas, 22 August 1999.

Hürriyet: TUPRAS set on fire by the stack, 24 August 1999.

Hürtaş, S.: Not earthquake but AKSA victims, Evrensel, 4 October 1999.

Hürtaş, S.: Not appropriate at all, Habertürk, 10 March 2009.

IARC: IARC monographs on the evaluation of carcinogenic risks to humans, Volume 71: Re-evaluation of some organic chemicals, hydrazine and hydrogen peroxide, IARC Working Group on the Evaluation of Carcinogenic Risks to Humans, Lyon, France, 1999.

IPCC: Climate change 2007: Synthesis report. Contribution of working groups I, II and III to the Fourth Assessment Report of the Intergovernmental Panel on Climate Change, IPCC, Geneva, Switzerland, 104 pp., 2007.

JICA: The study on a disaster prevention/mitigation basic plan in Istanbul including seismic microzonation in the Republic of Turkey, Final report, 2002.

Johnson, G., Aschheim, M., and Sezen, H.: Industrial facilities, Earthq. Spectra, 16, 311-350, 2000.

Kaplan, P.: AKSA spreads toxicity, Radikal, 5 September 1999.

Kılıç, A.: TUPRAS fire, Istanbul Technical University, Istanbul, 7 pp., 1999.

Kilic, S. A. and Sozen, M. A.: Evaluation of effect of August 17, 1999, Marmara Earthquake on two tall reinforced concrete chimneys, ACI Struct. J., 100, 357-364, 2003.

Krausmann, E.: Analysis of natech risk reduction in EU Member States using a questionnaire survey, Report, EUR 24661 EN, 2010.

Krausmann, E. and Baranzini, D.: Natech risk reduction in OECD Member Countries: results of a questionnaire survey, Report, JRC 54120, European Communities, 2009.

Official Journal: Public health law, 1439, 24 April 1930.

Official Journal: Regulation on structures to be built in disaster areas, 23390, 2 July 1998.

Official Journal: Regulation on permits for business startup and working, 25902, 10 August 2005.

Official Journal: Regulation on control of major industrial accidents, 27676, 18 August 2010.

Okay, O. S., Tolun, L., Telli-Karakoç, F., Tüfekçi, V., Tüfekçi, H., and Morkoç, E.: İzmit Bay (Turkey) ecosystem after Marmara Earthquake and subsequent refinery fire: the long-term data, Mar. Pollut. Bull., 42, 361-369, 2001.

Özmen, B.: Isoseismal map, human casualty and building damage statistics of the Izmit Earthquake of August 17, 1999, 3rd JapanTurkey Workshop on Earthquake Engineering, Istanbul, Turkey, 21-25 February 2000.

Parametrix: Hazardous waste and remediation, available at: http: //www.parametrix.com/pdf/HazardousWaste.pdf, access: 10 November 2010, 2002.

Parsons, T.: Recalculated probability of $M \geq 7$ earthquakes beneath the Sea of Marmara, Turkey, J. Geophys. Res., 109, B05304, doi:10.1029/2003JB002667, 2004.
Rahnama, M. and Morrow, G.: Performance of industrial facilities in the August 17, 1999 Izmit earthquake, in: Proceedings of the 12th World Conference on Earthquake Engineering, Auckland, New Zealand, 30 January-4 February 2000, 2851, 2000.

Reliance Industries: Types of refinery and Nelson's complexity, available at: http://www.ril.com/html/business/types_refinery. html, access: 25 March 2011.

Sabah: Second override decision for the AKSA, 25 January 2006.

Sezen, H. and Whittaker, A. S.: Seismic performance of industrial facilities affected by the 1999 Turkey earthquake, J. Perform. Constr. Fac., 20, 28-36, 2006.

Steinberg, L. J. and Cruz, A. M.: When natural and technological disasters collide: lessons from the Turkey Earthquake of August 17, 1999, Nat. Hazards Rev., 5, 121-130, 2004.

Steinberg, L. J., Cruz, A. M., Vardar-Sukar, F., and Ersoz, Y.: Hazardous materials releases during the August 17, 1999 earthquake in Turkey, in: Proceedings of the World Water and Environmental Resources Congress, Orlando, Florida, USA, 20-24 May 2001, 445, 2001.

Supreme Court: Decision on Ahmet Gök vs Aksa Acrylic Chemical Industry Corp. case, 4th Judicial Office of the Supreme Court, 2004/7006, 1 June 2004.

Suzuki, K.: Report on damage to industrial facilities in the 1999 Kocaeli earthquake, Turkey, J. Earthquake Eng., 6, 275-296, 2002.

Şengör, S. S.: Modeling contaminant transport and remediation at the AKSA acrylonitrile spill site, M.S. thesis, Department of Environmental Engineering, Middle East Technical University, Ankara, Turkey, 103 pp., 2002.

Şenocaklı, M.: The Chernobyl at Yalova, Vatan, 9 July 2003.

Şenocakl1, M.: We escaped leaving people behind under the debris, Vatan, 10 July 2003.

Şenocakl1, M.: This place is not like Yalova but the AKSA town, Vatan, 14 July 2003.

TUPRAS: Annual Report 2009, Istanbul, Turkey, 175 pp., 2010.

Türk, E.: Poison of the AKSA killed fish in the area, Milliyet, 9 September 1999.

van Aalst, M. K.: The impacts of climate change on the risk of natural disasters, Disasters, 30, 5-18, 2006.

Voice of Yalova: Lawyer Ayşe Aydemir, available at: http: //yalovaninsesi.com/Haberler/Av-Ayse-AYDEMiR.html, access: 5 November 2010.

Yeletaysı, S.: August, 17th 1999 TÜPRAŞ refinery fire: a case study in crisis and disaster management, Turk. J. Disaster, 2, 1-9, 2007.

Zaman: Supreme court: Penalty given to Chernobyl of Yalova is insufficient, 9 October 2005.

Zanbak, C.: Aquifer remediation and chemical recovery following a spill due to an earthquake in Turkey, in: Methods and techniques for cleaning-up contaminated sites, NATO Science for Peace and Security Series C: Environmental Security, edited by: Annable, M. D., Teodorescu, M., Hlavinek, P., and Diels, L., Springer, Netherlands, 91-101, 2008. 